\title{
PROPERTIES OF CEMENT-TREATED SOILS DURING INITIAL CURING STAGES
}

\author{
SOCHAN SENG ${ }^{\mathrm{i})}$ and HIROYUKI TANAKA ${ }^{\mathrm{ii}}$
}

\begin{abstract}
The engineering properties of cement-treated soils manufactured by the so-called "Pipe Mixing Method" and "Super GeoMaterial (SGM) Method" were studied. In these methods, clayey soils with high water contents are mixed with cement and used as fill material. Since the cement-mixed soils are transported through a pipeline, whose length at times exceeds $2 \mathrm{~km}$, the properties of the treated soil during the initial stages of the hardening process are important. Bender element, vane shear and fall cone tests were performed to obtain such engineering properties as the shear modulus and the shear strength. The study revealed the following: 1) The minimum shear wave velocity of treated soils is detectable at around $2.8 \mathrm{~m} / \mathrm{s}$, corresponding to a shear modulus of about $12 \mathrm{kPa}$. 2) A linear correlation between the shear modulus and the shear strength exists even in the very early stages of curing, approximately $G=300 \mathrm{~s}$, where $G$ and $s$ are the shear modulus and the shear strength, respectively. This relation is similar to that for natural clays. 3) The "setting time" observed for concrete is also apparent in cement-treated soil materials. 4) Fall cone tests comprise a useful and simple technique for measuring very low levels of shear strength.
\end{abstract}

Key words: bender element, cement-treated soil, fall cone, hardening process, shear modulus, shear strength, vane shear (IGC: D6/D10)

\section{INTRODUCTION}

Reclamation materials are in great demand for coastal development projects in Japan. Traditionally, sandy soils and crushed rock have been used as fill material. However, this practice causes an unfavorable impact on ecological systems. On the other hand, large quantities of soft clay or mud are produced during the maintenance of navigation channels, and a disposal sites are required for the soils. To cope with these problems, dredged soils with high water contents have gradually come into use for land reclamation in Japan.

Due to the undesirable material properties of these dredged soils, for example, low strength and high compressibility, soil improvement, such as with vertical drains, is necessary to reduce the residual settlement. However, such methods are not appropriate because of the difficulty of employing heavy machinery for the drain installation, due to the very low strength, and because of the time required for consolidation after the placement of the drains. Instead, methods are used in which clayey soils are mixed with cement at a plant, as well as during transportation to filling sites, methods referred to as the "Pipe Mixing Method" or the "Super GeoMaterial (SGM) Method" (Tsuchida, 1995; Tsuchida et al., 1996; Satoh et al., 2001; Otani et al., 2002; Tsuchida and Egashira, 2004). Another advantage of cement treatment is that, due to its high water content, it has a small unit weight, which can significantly reduce the lateral earth pressure acting on retaining structures and the overburden pressure causing settlement in the original ground.

Although the properties of cement-treated soil (CTS) have been extensively studied by many researchers (for example, Terashi and Tanaka, 1981; Terashi et al., 1983; Miura et al., 2001; Lee et al., 2005; Flores et al., 2010), these properties are mainly targeted as materials produced by the "Deep Mixing (DM) Method", which treats the in situ soil in such a way that the water content is relatively moderate and the curing time is longer than one week. Alternatively, soils used in the Pipe Mixing or the SGM Method have high water contents, and the treated soil should behave as a liquid in the early stages, because it must be transferred through a pipe to the construction site. In some cases, the pumping distance may be longer than $2 \mathrm{~km}$. Therefore, if the material is too stiff, the soil cannot be transported due to high resistance. However, both the water content and the cement ratio should be monitored so that the treated soil can solidify and attain the desired strength. The ability to transport CTS may be governed by several factors, such as shear strength, rigidity and viscosity. As pointed out by Jeong et al. (2010), for example, the viscosity of clay is still not well understood, including its measurement, compared with shear strength and rigidity. Therefore, the focus of this study is

i) PhD Student, Hokkaido University, Japan.

ii) Professor, ditto (tanaka@eng.hokudai.ac.jp).

The manuscript for this paper was received for review on July 5, 2010; approved on April 12, 2011.

Written discussions on this paper should be submitted before May 1, 2012 to the Japanese Geotechnical Society, 4-38-2, Sengoku, Bunkyo-ku, Tokyo 112-0011, Japan. Upon request the closing date may be extended one month. 
placed mainly on the conventional mechanical properties, i.e., shear strength and rigidity, during the hardening process of CTS.

Even though specific testing standards for CTS in the DM method have already been established, the behavior of CTS with a high water content during the initial stages of curing remains unknown and testing methods for evaluating these properties have not yet been proposed. Reasons for the limited studies carried out in this field may be attributed to the difficulty of sample preparation and the inappropriate selection of testing techniques. The strength of the targeted soil for the DM method is generally large enough to make a specimen such that unconfined compression tests comprise the most standard test method for the evaluation of its properties. Various properties such as tensile strength or shear modulus have been correlated with unconfined compressive strength $\left(q_{\mathrm{u}}\right)$ values and practical correlations have been established (for example, Terashi et al., 1983; Lee et al., 2005; Flores et al., 2010).

In this research, a nondestructive bender element test was introduced to investigate the development of stiffness at very low levels of strain. The measurement can be performed on a single specimen at any specific curing time during the hardening process. Vane shear tests and fall cone tests were also employed to determine and compare the shear strength at a very soft state. A more suitable testing technique was suggested for evaluating the properties of CTS in the early stages of the hardening process. Consequently, a correlation between the stiffness and the strength of the CTS material over a wide range is presented.

\section{SAMPLE PREPARATION}

Two commercially-available clays, Fujinomori and Kasaoka, were selected for obtaining the fundamental properties of CTS. The reason for choosing these two types of clay was that even their physical properties are similar, namely, Kasaoka clay consists of smaller clay particles with higher plasticity, while Fujinomori clay contains some amount of quartz and has higher permeability. These special characteristics provided two varieties of soil samples for this research. However, the properties of these clays differ from typical Japanese marine clay or sediments; therefore, Tokyo Bay clay was used to confirm the applicability of the test results. The index properties of the clays are summarized in Table 1.

Test specimens were prepared under various water contents $(w)$ and cement contents $(C)$. In this paper, $C$ is defined as the ratio of cement to the dry weight of the soil. For commercial clays, powdered clay was mixed with distilled water to a water content less than the targeted water content, at least one day before testing. Additional distilled water and powdered Portland cement were added to the slurry and mixed thoroughly with a mixer for 10 minutes. Following the mixing, samples with a wet density that varied from 1.27 to $1.67 \mathrm{~g} / \mathrm{cm}^{3}$ were cast in cylindrical molds at the sizes shown in Table 2. During the
Table 1. Physical properties of soil samples

\begin{tabular}{ccccc}
\hline Soil type & $\begin{array}{c}\text { Plastic } \\
\text { limit (\%) }\end{array}$ & $\begin{array}{c}\text { Liquid } \\
\text { limit (\%) }\end{array}$ & $\begin{array}{c}\text { Plasticity } \\
\text { index }\end{array}$ & $\begin{array}{c}\text { Particle density } \\
\left(\mathrm{g} / \mathrm{cm}^{3}\right)\end{array}$ \\
\hline Fujinomori & 26 & 51 & 25 & 2.69 \\
Kasaoka & 28 & 62 & 34 & 2.61 \\
Tokyo Bay & 33 & 103 & 70 & 2.72 \\
\hline
\end{tabular}

Table 2. Specimen size for different tests

\begin{tabular}{ccc}
\hline Testing method & Diameter $(\mathrm{mm})$ & Height $(\mathrm{mm})$ \\
\hline Bender element & 50 & 100 \\
Vane shear & 200 & 70 to 80 \\
Fall cone & 100 & 30 \\
Unconfined compression & 50 & 100 \\
\hline
\end{tabular}

casting, the samples were vibrated to remove any air bubbles within the specimens. As mentioned earlier, due to the high permeability of Fujinomori clay, bleeding was observed during the early stages of curing in the case of a high water content. In contrast, Kasaoka clay did not show such a phenomenon even with the high range of water content used in this experiment. Under such mixing conditions, only one specimen was needed for the bender element tests, while many specimens were required for the unconfined compression tests in which the specimens were cured to gain adequate strength. For the vane and the fall cone tests, samples with large volume were prepared to carry out these tests on various points, as indicated in Table 2 .

\section{TESTING METHODS}

\section{Bender Element Tests}

Bender element testing has been extensively used in the field of geotechnical research as a nondestructive testing method for geomaterials (Shibuya et al., 1997; Horng et al., 2010), including cement-treated clay for the DM method (Flores et al., 2010). Bender element tests allow for the repeatability of shear wave velocity $\left(V_{\mathrm{s}}\right)$ or shear modulus $(G)$ measurements in the same sample at any specific curing time. A schematic view of the bender element system is shown in Fig. 1(a). A bender element of the parallel type, $10 \mathrm{~mm}$ in length, $10 \mathrm{~mm}$ in width, and $0.5 \mathrm{~mm}$ in thickness, was used as the transmitter, and a bender element of the series type, $13 \mathrm{~mm}$ in length, 10 $\mathrm{mm}$ in width, and $0.5 \mathrm{~mm}$ in thickness, was used as the receiver. Both types were coated with epoxy glue for waterproofing. The transmitter element was assembled with a light acrylic cap, while the receiver was attached with a brass pedestal whose protrusion lengths were about 7 and $9 \mathrm{~mm}$, respectively. The shear waves generated by the function generator are transmitted by a bender element placed on the top of the specimen. The receiver element at the base is then bent by the arrival of the shear waves and generates a certain voltage. Input signals, as well as received signals, are displayed in a digital oscilloscope, such that each shear wave is identified and its ve- 

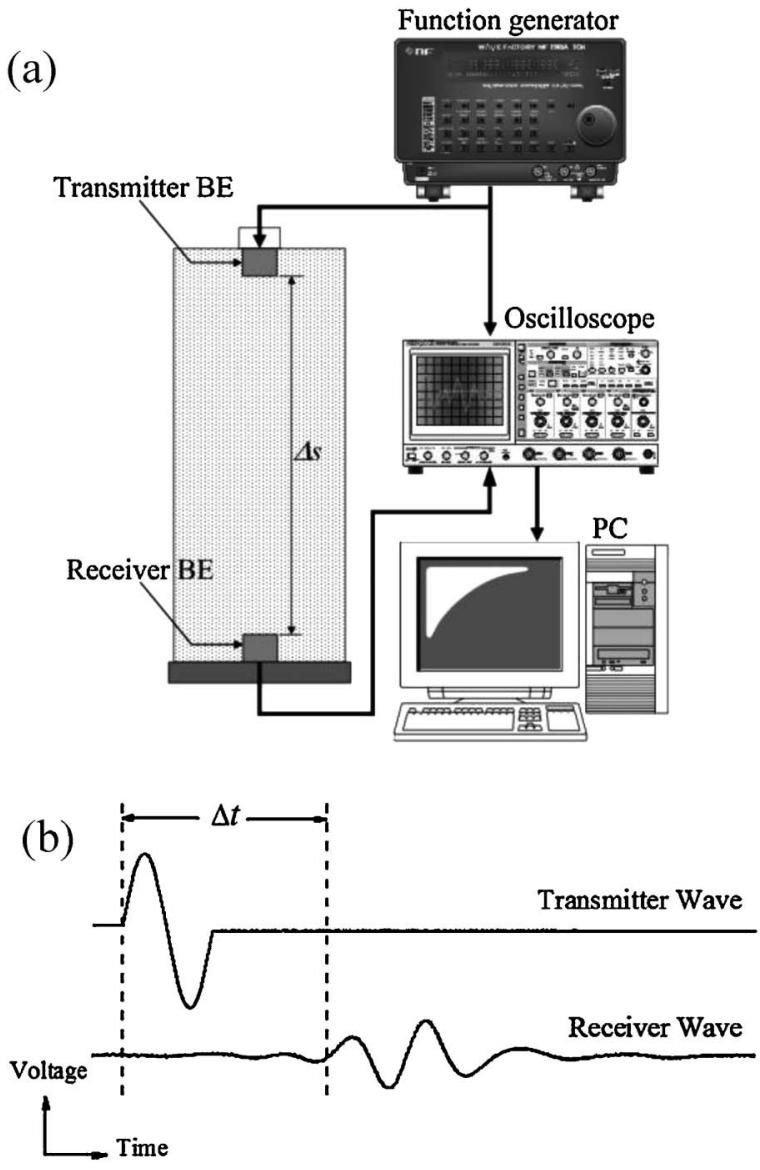

Fig. 1. (a) Schematic view of bender element system and (b) Travel time measurement method

locity can be calculated. The "start-to-start" method for defining the arrival times, i.e., $\Delta t$ in Fig. 1(b), and the "tip-to-tip" method for determining the travel distances of the shear waves, i.e., $\Delta s$ in Fig. 1(a), were adopted (for details, refer to Viggiani and Atkinson, 1995; Kawaguchi et al., 2001; Yamashita et al., 2009). $V_{\mathrm{s}}$ can be calculated from Eq. (1) as

$$
V_{\mathrm{s}}=\frac{\Delta s}{\Delta t}
$$

$G$ can be derived from $V_{s}$, through the shear wave propagation in the elastic body theory, as shown in Eq. (2).

$$
G=\rho \cdot V_{s}^{2}
$$

where $\rho$ is the total density of the soil specimen.

It should be pointed out that measured $V_{\mathrm{s}}$ is affected by the plastic mold, but that the rigidity of CTS is much smaller than that of the mold, so that the arrival time of the shear waves propagated through CTS can be clearly identified.

\section{Vane Shear Tests}

Due to the low shear strength of CTS at the early stages, conventional triaxial or unconfined tests cannot be performed. Thus, vane shear tests are employed in this study. The shear strength $(s)$ is calculated by Eq. (3), namely,

$$
s=\frac{2 T}{\pi \cdot D^{2} \cdot\left(H+\frac{D}{3}\right)}
$$

where $T$ is the measured torque at peak, $D$ is the vane diameter, and $H$ is the vane height.

The vane diameter and the vane height employed in this experiment were 20 and $40 \mathrm{~mm}$, respectively. The shear rate of the laboratory vane apparatus was constant at $6^{\circ}$ rotations per minute. In the experiment, the vane blade was inserted at a point selected away from the previously tested points so as not to be influenced by the disturbance caused by the previous tests. To attain more accurate results, two different maximum load cell capacities, $1 \mathrm{~N}$ and $20 \mathrm{~N}$, were alternately used according to the shear strength of the material. When utilizing the 1-N load cell, the accuracy of the shear strength acquired was as small as $1.7 \mathrm{~Pa}$.

\section{Fall Cone Tests}

The cone angle and the weight for the fall cone used in this study were $60^{\circ}$ and $60 \mathrm{~g}$, respectively. The penetration of the cone is usually measured by a dial gauge. However, to evaluate the effects of the reaction to the cement hydration on the cone penetration, the fall cone apparatus was equipped with a laser to enable the measurement of the cone displacement with time. The tests were run by placing the cone tip on the surface of each specimen in a cylindrical cup. The cone was allowed to fall freely under its own weight. Similar to the vane shear tests, the cone was dropped at a point selected away from the previously tested points. During penetration, the cone movement was monitored by recording the penetration $(h)$ every $0.001 \mathrm{~s}$. The shear strength $(s)$ from the fall cone tests was determined by the penetration depth after $5 \mathrm{sec}-$ onds, using the following empirical formula proposed by Hansbo (1957):

$$
s=\frac{K \cdot W}{h^{2}}
$$

where $K$ is the cone factor which depends on the cone angle. For a $60^{\circ}$ cone, $K$ is equal to 0.29 (Wood, 1985). $W$ and $h$ are the weight of the cone and the depth of the cone penetration, respectively.

The time required to perform the fall cone tests was shorter than that for the vane shear tests, which was an advantage for the CTS testing and will be discussed later.

\section{SHEAR WAVE VELOCITY AND SHEAR MODULUS}

The plots in Fig. 2 show typical examples of the increase in the value of $V_{\mathrm{s}}$ with the curing time from the bender element tests. In the figure, Kasaoka clay was mixed to a water content of $80 \%$ and a cement content of $4 \%$. In these tests, the voltage of the input pulse for both the sine and the rectangular waves was constant $( \pm 10 \mathrm{~V})$; however, its frequency was varied to search for the optimum output signals to avoid any influences caused by undesired noises such as the near-field-effect (see Yamashita 


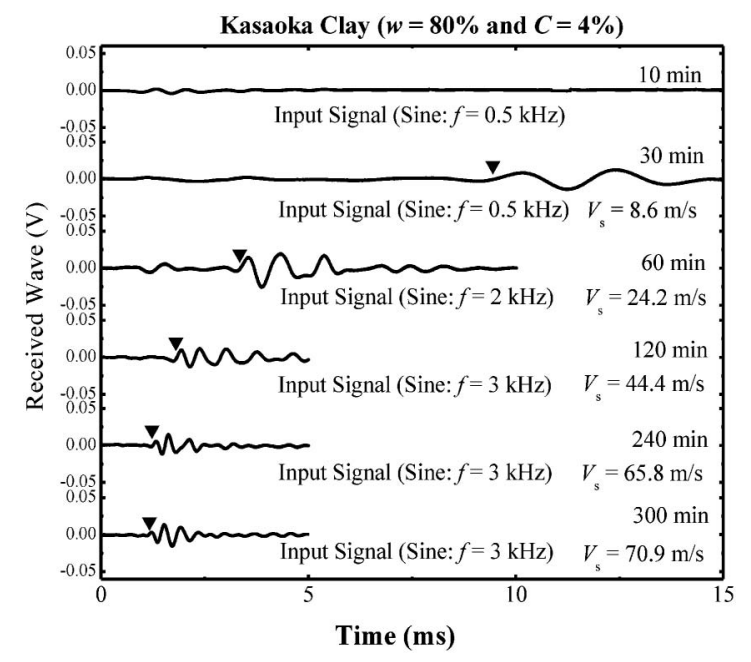

Fig. 2. Typical example of $V_{\mathrm{s}}$ measurement

et al., 2009). Throughout the measurement process, frequencies of the input pulse were increased according to increases in the curing time or the soil stiffness. For the purpose of this study, the start of the curing time was defined as the time when the mixing had been completed and the mixed soil had been poured into the mold. Immediately after the mixing (approximately 10 min of curing time), no shear wave signal could be detected, as shown in Fig. 2. The fact that shear waves could not propagate through the liquid indicates that the specimen was still soft and in a "liquid" phase. After $30 \mathrm{~min}$, a shear wave started to be observed, but its amplitude and frequency were low. The defined arrival time is represented by the symbol $\nabla$ in Fig. 2; the $V_{\mathrm{s}}$ value is around $8.6 \mathrm{~m} / \mathrm{s}$ at this time. As the curing time increased, the arrival time became shorter, in other words, the magnitude of $V_{\mathrm{s}}$ increased. Also, the wavelengths became shorter corresponding to the input signals.

Measurement of the shear modulus $(G)$ was performed using bender element tests on a total of thirteen CTS samples. Seven samples were Fujinomori clay and the other six were Kasaoka clay. The Fujinomori clay was prepared at water contents ranging from 60 to $80 \%$, while the Kasaoka clay was prepared at water contents ranging from 80 to $160 \%$. The cement content varied from 4 to $10 \%$ for both clays.

The plots in Fig. 3(a) depict the variation in measured $G$ with curing times for all thirteen samples. Generally, the $G$ values are seen to increase with the curing time. However, some samples, for example, $w: C=60: 4$ and $w: C=70: 4.7$, showed an almost constant $G$ value. Nonetheless, by using a $\log$ scale for $G$, as presented in Fig. 3(b), a slight increase in $G$ is identified because the bender element is quite sensitive and is able to detect even a small change in the material stiffness. From all the tests in this study, it was found that the minimum $V_{\mathrm{s}}$ detectable by the bender element tests was around $2.8 \mathrm{~m} / \mathrm{s}$, corresponding to a $G$ of about $12 \mathrm{kPa}$. Looking at these figures, the development rate of $G$ was apparently affected by many factors, including soil properties, the amount
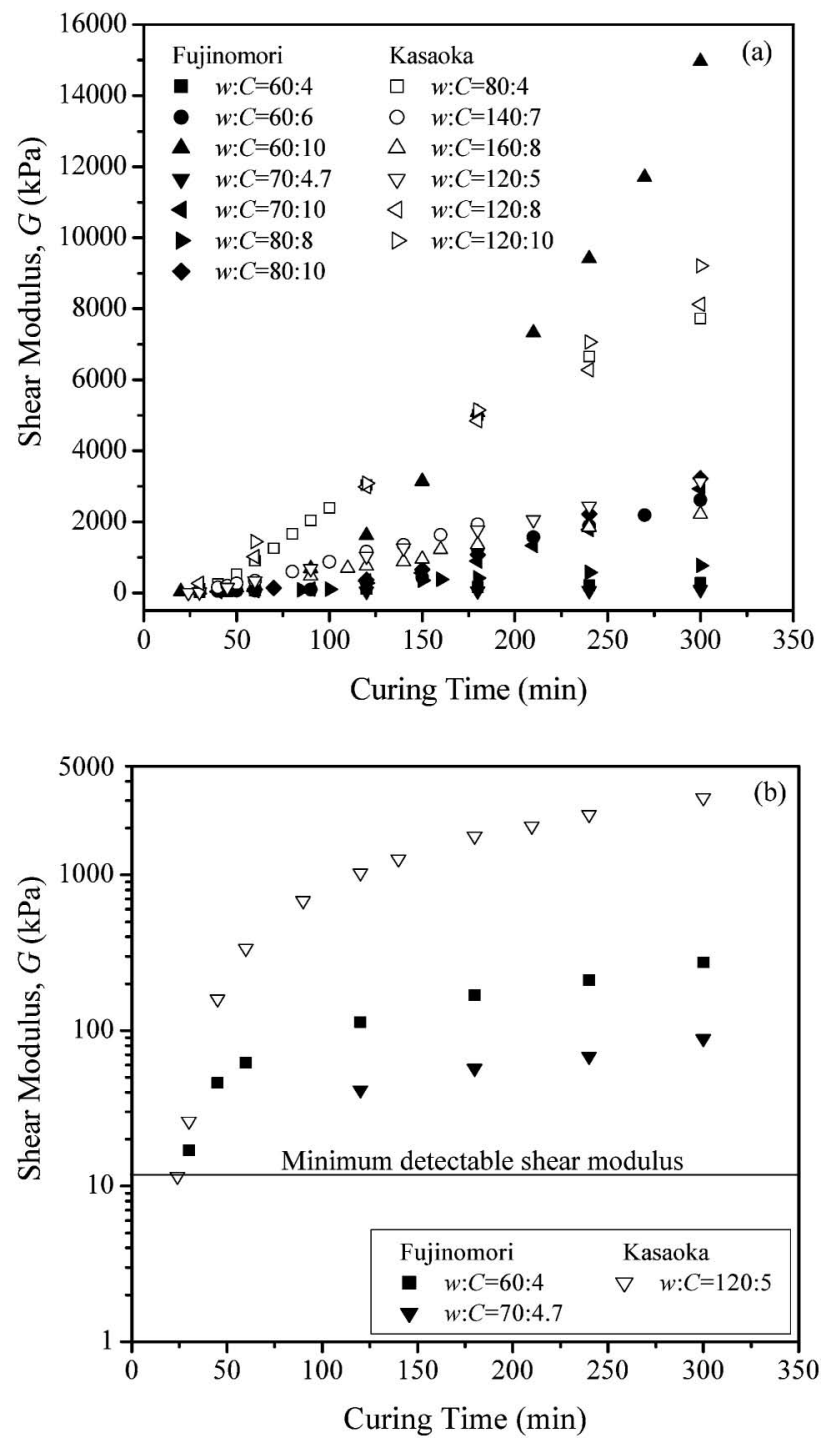

Fig. 3. Variation in shear modulus with curing time

of water and the cement content. As expected, under the same water content, the samples (the same soil types) with a higher quantity of cement possessed a greater $G$.

Figure 4(a) illustrates the normalized $G$ at a curing time of $120 \mathrm{~min}$. It is of interest to note that the large scattered plots in Fig. 3(a) are strung into a narrow band up to a certain time (in this case, about $150 \mathrm{~min}$ ) and then increase differently depending on the mixing conditions. The scale in Fig. 4(a) has been enlarged and is shown in Fig. 4(b). Although some scatter is shown in the enlarged scale, a clear relation between the normalized $G$ and the curing time can be recognized. Important findings for the curing process are that $G$ increases linearly with the curing time after a certain elapsed time and that there exists a "dormant period" in this relation. At a curing time of less than approximately $20 \mathrm{~min}$, the cement-treated soil behaves as a liquid and the shear modulus cannot be measured. This period may correspond to the "setting time" in concrete. As seen in Fig. 4(a), in spite of the wide range in mixing conditions, the setting time of 20 min is apparently influenced by neither $w$ nor $C$. It is 

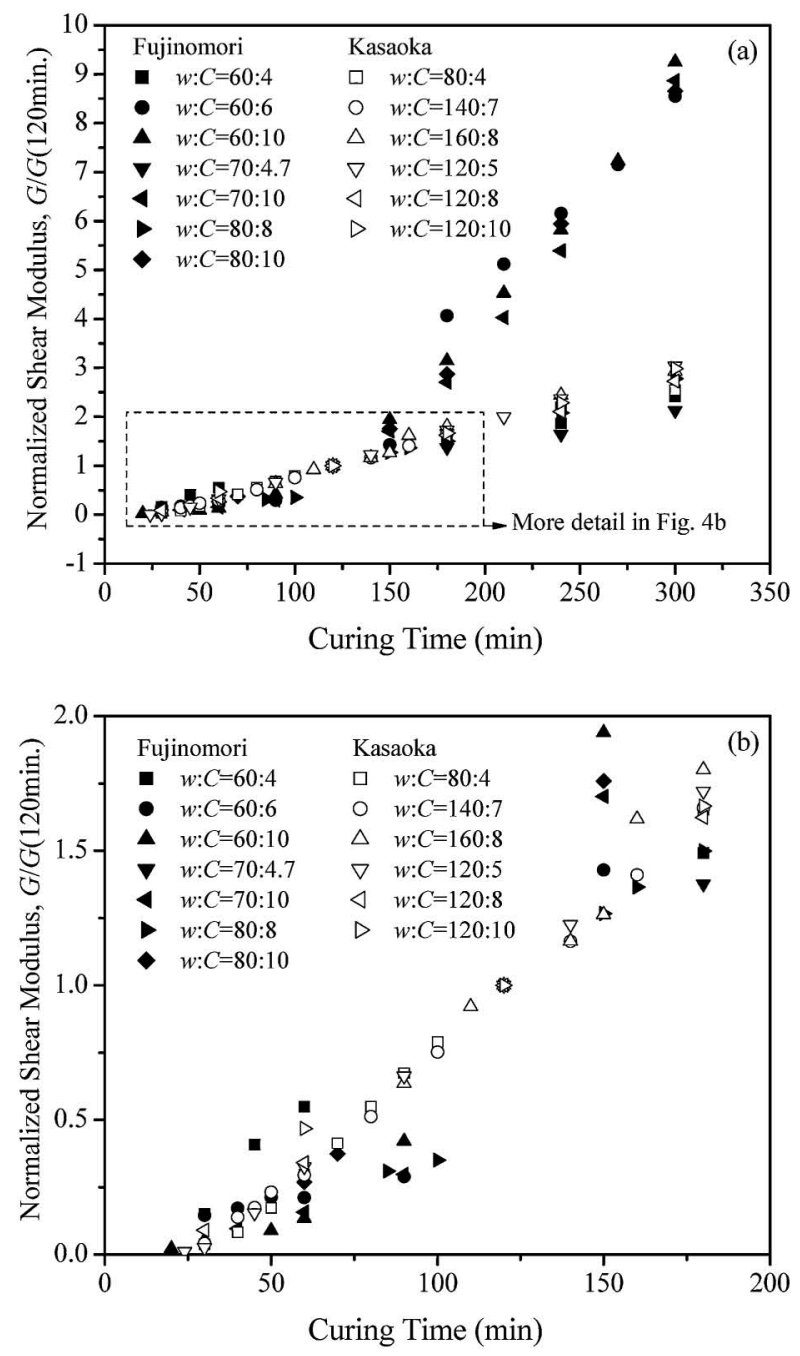

Fig. 4. (a) Normalized $G / G(120 \mathrm{~min})$ versus curing time and (b) enlarged scale

necessary to confirm whether this fact can be applied to any mixing conditions and to investigate what mechanism is developed in CTS during this period, using for example, a Scanning Electron Microscope (SEM).

At real construction sites, where large amounts of CTS are treated, some fluctuation in the water content of the dredged soils cannot be avoided. To cope with such variability in the water content, the amount of cement is, in practice, determined based on the concept of the constant $W / C$ ratio, where $C$ and $W$ are the amounts of cement and water in the soil, respectively. The background of this concept is that the properties of CTS, especially the strength, are controlled by $W / C$. When the water content in a soil is higher than the initial target, the volume of cement should be increased accordingly.

Figures 5(a) and (b) show the variation in $G$ with the $W / C$ ratio at two different curing times, i.e., 60 and 300 min, respectively. As shown in Figs. 4(a) and (b), the curing time of 60 min corresponds to the time when the normalized $G$ linearly increases regardless of the mixing conditions and 300 min corresponds to the time when $G$ no longer follows this relation. Overall, $G$ increases as the
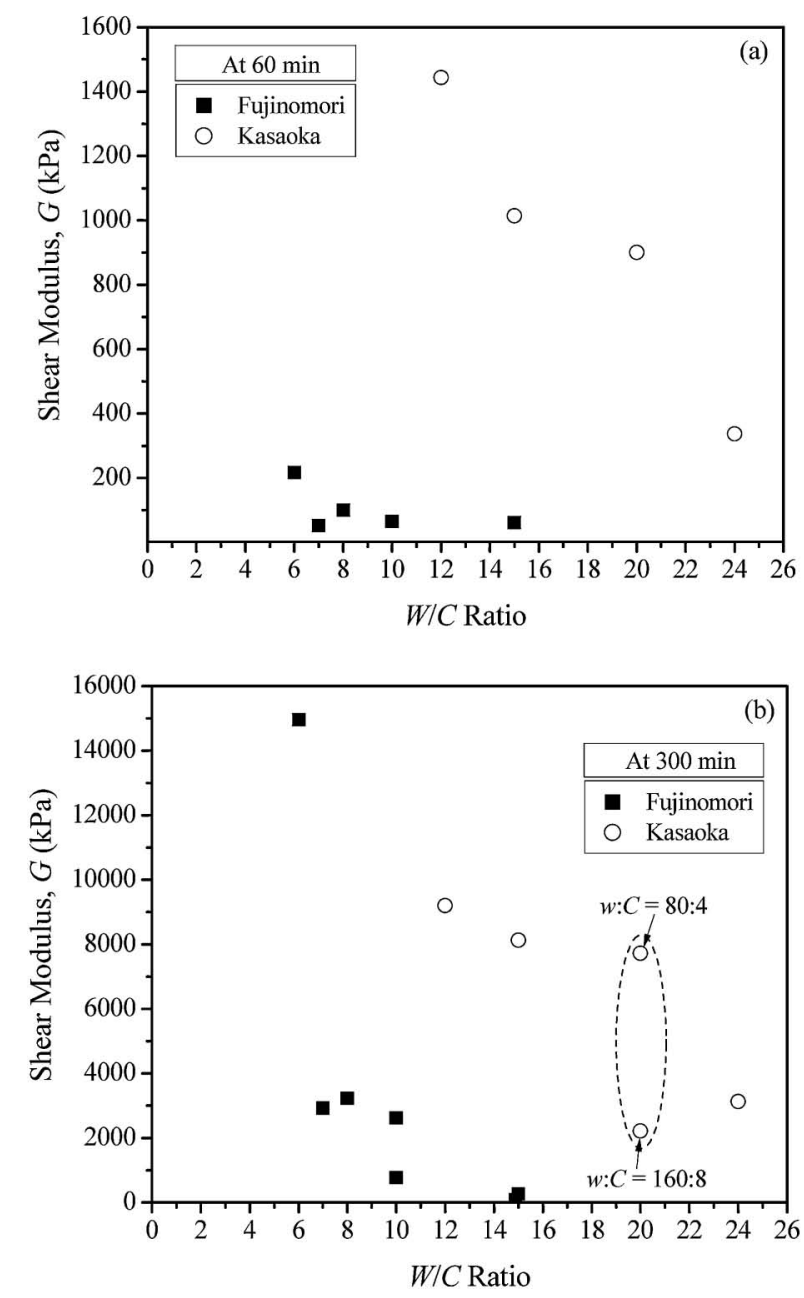

Fig. 5. Variation in $G$ with $W / C$ ratio at curing times of (a) $60 \mathrm{~min}$ and (b) $300 \mathrm{~min}$

$W / C$ ratio decreases. In each figure, the $G$ for Kasaoka clay is larger than that for Fujinomori clay at any $W / C$ ratio. This means that the concept of a constant $W / C$ ratio cannot be applied if the soil is different. In addition, it was found that $W / C$ does not always define $G$, even for the same soil, when the mixing conditions are extremely different. For instance, $G$ for $w: C=80: 4$ and $w: C=160: 8$ for Kasaoka clay, whose $W / C$ ratio is the same as 20 , are plotted in Fig. 5(b). Nonetheless, the $G$ value of a sample with a lower water content is more than 3 times higher. Hence, it can be concluded that using the $W / C$ ratio to determine the amount of cement is acceptable to a certain range of water content and that the CTS behavior is strongly affected by the soil properties.

\section{SHEAR STRENGTH}

Vane Shear Tests

Figure 6(a) shows a typical example of shear stress versus angular rotation relationships from the vane shear tests. These curves were obtained from a mixture of Kasaoka clay with a water content of $120 \%$ and a cement content of $5 \%$ measured at six different curing times, namely, 30, 60, 140, 180, 240, and $300 \mathrm{~min}$. It can be seen 

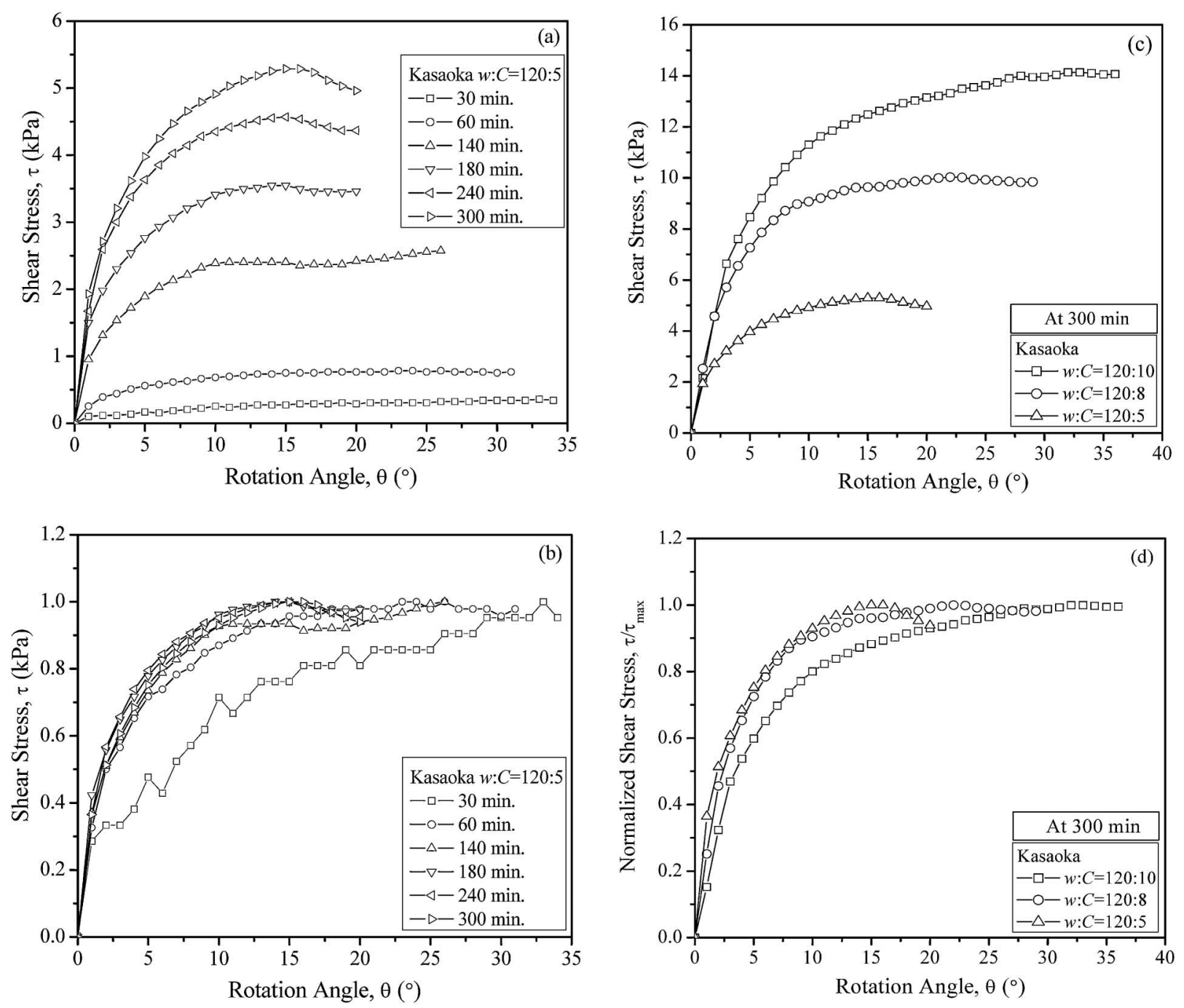

Fig. 6. Typical example of vane shear test results (a) $\tau-\theta$ relationships, (b) normalized $\tau / \tau_{\max }-\theta$; and different samples measured at curing time of $300 \mathrm{~min}$ (c) $\tau-\theta$ relationships and (d) normalized $\tau / \tau_{\max } \theta$

that the level of shear stress for each curve increases monotonically with deformation and reaches the maximum magnitude at an angular rotation of around 15 to $30^{\circ}$. Noting that the rotation speed in the vane tests is $6^{\circ}$ per minute, it takes about 3 to $5 \mathrm{~min}$ to reach failure. These times cannot be ignored, especially at the early curing stages when the solidification process is prominent. This shows one drawback of the vane shear tests applied to evaluate the strength for early increments in the curing process, compared with fall cone tests, with which measurements can be completed in 5 seconds, and with bender element tests, where its level of strain is very small. Figure 6(b) shows the shear stress and angular rotation relation from Fig. 6(a), normalized by its corresponding maximum shear stress. It should be noted that the scatter in the relation for $30 \mathrm{~min}$ is significant, but this is because the measured stress is very small. As can be seen in these two figures, the curves with curing times of less than approximately 140 min show long strain-hardening behavior, from which the maximum shear stress is obtained at a large rotation angle. This means that if the solidification process remains prominent, the destruction of CTS due to the rotation of the vane might be somewhat interfered by healing due to the hydration reaction of the cement. As the curing time proceeds, the cement hydration becomes less significant; thus, the maximum stress is attained at a smaller rotation angle. In addition, the prominence of the reaction period is also dependent on the quantity of the cement, as indicated in Figs. 6(c) and (d). In these figures, three Kasaoka samples, with equal water contents but with different amounts of cement, were measured through vane tests at a curing time of $300 \mathrm{~min}$. The shear stress of the sample with the highest amount of cement, i.e., $w: C=120: 10$, reached failure at the very high rotation angle of about $30^{\circ}$, while the $w: C=120: 5$ sample reached failure at the rotation angle of only $15^{\circ}$. It can be concluded, therefore, that higher quantities of cement result in longer solidification periods. However, it can be shown that beyond a certain rotation angle, the shear strength relationship is not affected by the curing time. Thus, vane tests can measure the strength properly even at very early stages.

To investigate the strength development of CTS, vane shear tests were conducted during the hardening process 

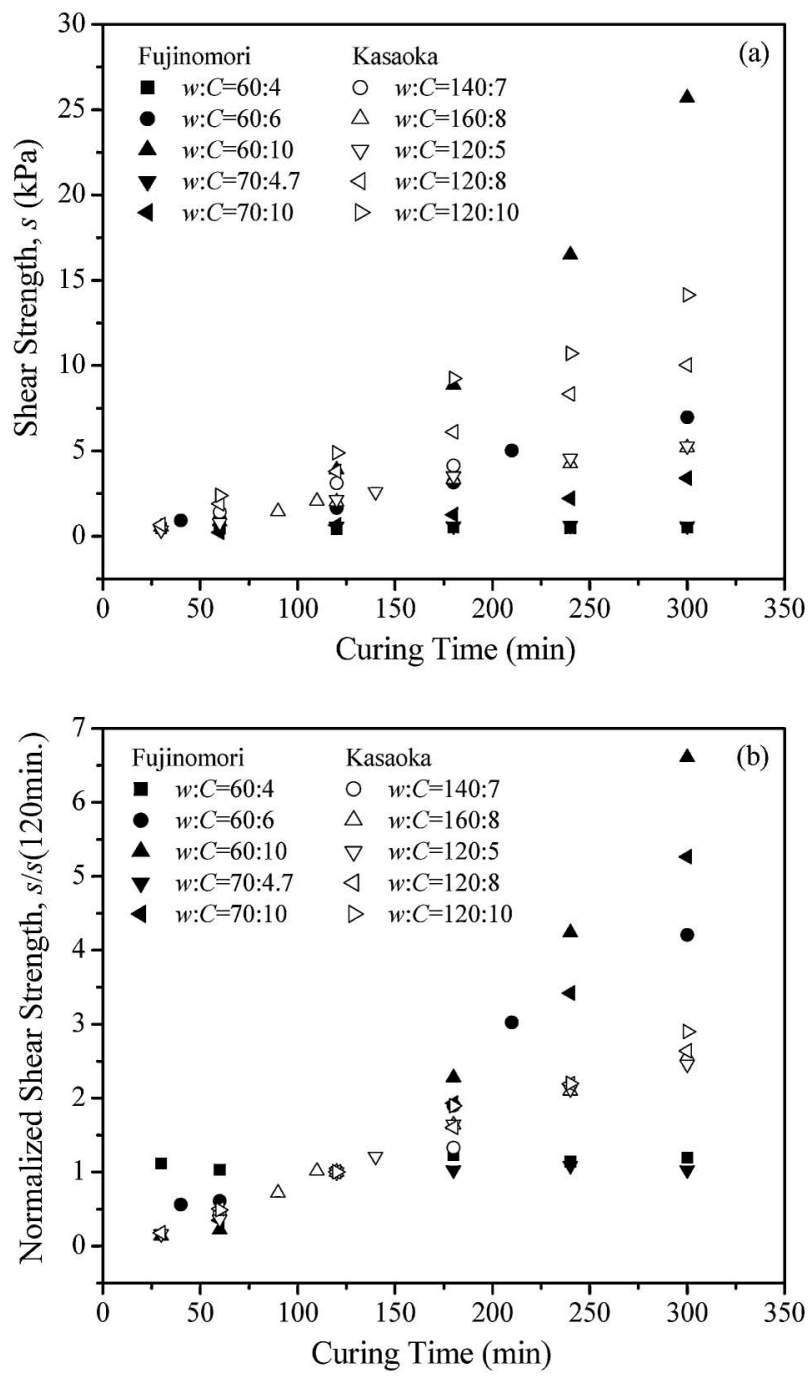

Fig. 7. (a) Variation in shear strength with curing time and (b) normalized $s / s(120 \mathrm{~min})$

to a curing time of $300 \mathrm{~min}$. The test results are summarized in Fig. 7(a) for both Fujinomori and Kasaoka clays. Similar to the $G$ values measured in the bender element tests, the strength increases with the curing time. The rate of increase is dependent on the mixing conditions. Obviously, at the same water content, samples with more cementing agent show higher levels of strength.

The large variation in strength shown in Fig. 7(a) was normalized in the same way as $G$, i.e., the shear strength is normalized by that at $120 \mathrm{~min}$ in Fig. 7(b). Although the variation in shear strength is considerably reduced, large scatters in this relation still exist, compared with the normalized $G$ shown in Fig. 4(a). For example, in the case of $w: C=60: 4$ and $w: C=70: 4.7$ for Fujinomori clay, the normalized strength is nearly constant with the curing time. This is due to the difference in the accuracy of the measurements between the vane shear and the bender element tests, or to the fact that the shear strength has not developed in the same manner as $G$. This point will be discussed in further detail in the next chapter.

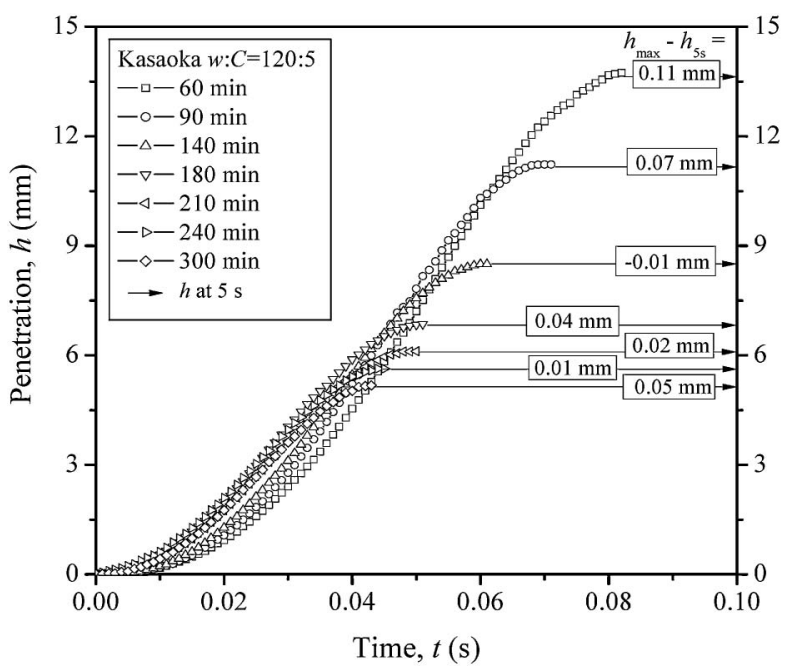

Fig. 8. Movement of cone penetration versus time from fall cone tests
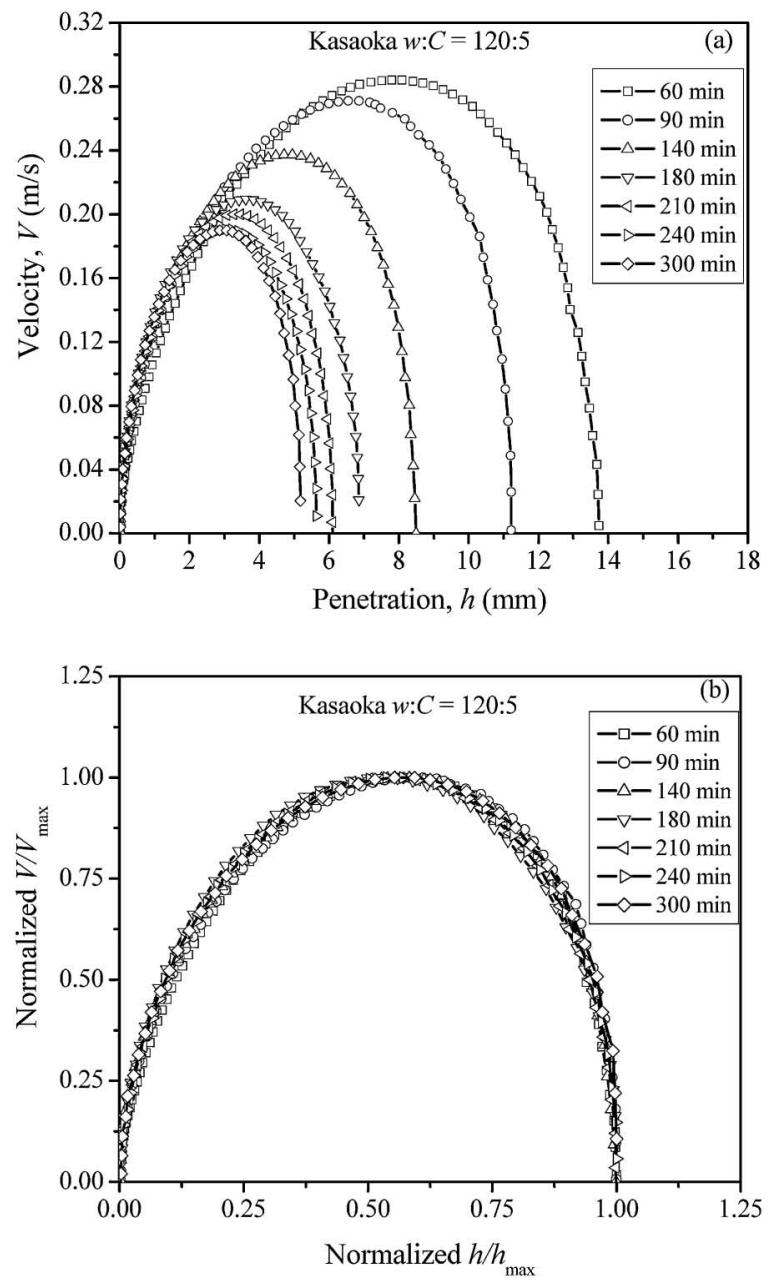

Fig. 9. Relation between cone velocity and penetration depth (a) $V$ - $h$ and (b) $V / V_{\max }-h / h_{\max }$

\section{Fall Cone Tests}

Figure 8 shows the results of fall cone tests on Kasaoka clay mixed at a water content of $120 \%$ and a cement content of $5 \%$. In this figure, the cone penetration $(h)$ with 
time $(t)$ is plotted at several specific curing times from 60 to $300 \mathrm{~min}$. As the curing time proceeds, the penetration depth decreases due to hardening. It is interesting to note that as the penetration depth decreases, the time required to reach the steady state also becomes shorter, that is, the relationship between penetration and time is not greatly affected by the curing time. For instance, at $60 \mathrm{~min}$, a maximum depth of $13.7 \mathrm{~mm}$ is reached at $0.08 \mathrm{~s}$, while at $300 \mathrm{~min}$, the maximum depth decreases to $5.2 \mathrm{~mm}$, which corresponds to a penetration time of $0.04 \mathrm{~s}$. The times required for the cone to reach the maximum depth are relatively short for all cases, i.e., less than $0.10 \mathrm{~s}$. According to worldwide testing standards, including those of the JGS (Japanese Geotechnical Society), the penetration depth is defined at $5 \mathrm{~s}$. Additional penetration after reaching the steady state at $5 \mathrm{~s}$ is indicated in the figure; however, this difference is very small and its value is less than $1 \%$ of the total penetration. From this study, it may be concluded that $5 \mathrm{~s}$ is long enough to allow the cone to reach a stable condition and to facilitate the operation of manual reading using a dial gauge.

To present further evidence regarding the effects of hardening on cone penetration, the cone velocity $(V)$ through the depth $(h)$ and its normalization $\left(V / V_{\max }\right.$ versus $h / h_{\max }$ ) are plotted in Figs. 9(a) and (b), respectively. The velocity is derived from the movement of the cone shown in Fig. 8. As can be seen in Fig. 9(a), the relations of $V$ and $h$ appear differently according to the curing times. The CTS at the early curing times possesses a higher maximum $V$. Nevertheless, it can be normalized to a single curve, as shown in Fig. 9(b). This means that the speed of the penetration changes proportionally to its corresponding depth. This fact indicates that the cone movements during penetration are not influenced by the different stages of hydration reaction at various curing times because the penetration speed is considerably high compared to the rotation in the vane shear tests.

\section{Comparison of Vane Shear and Fall Cone Tests}

Using Kasaoka clay treated with four different water and cement content conditions, a comparison of the levels of shear strength between the vane shear and the fall cone tests was made. The comparison is shown in Figs. 10 and 11. It can be seen that at low levels of shear strength, i.e., about $3 \mathrm{kPa}$, or at curing times of less than $180 \mathrm{~min}$, the strength measured by the fall cone tests is slightly smaller than that by the vane tests. Nonetheless, soon after the strength measured by the fall cone tests begins to increase. The reason for these differences may be explained by the inconsistency of the shearing patterns. Moreover, it is true that when CTS becomes stiff, the accuracy of the fall cone tests may be reduced due to the small penetration depth caused by the insufficient cone weight. However, as variations in these strengths are concentrated in a relatively narrow band, the results obtained by these two methods are considered comparable. The fall cone tests are faster and easier to perform than the vane tests. Therefore, fall cone tests are recommended for use in checking the properties of CTS at construction

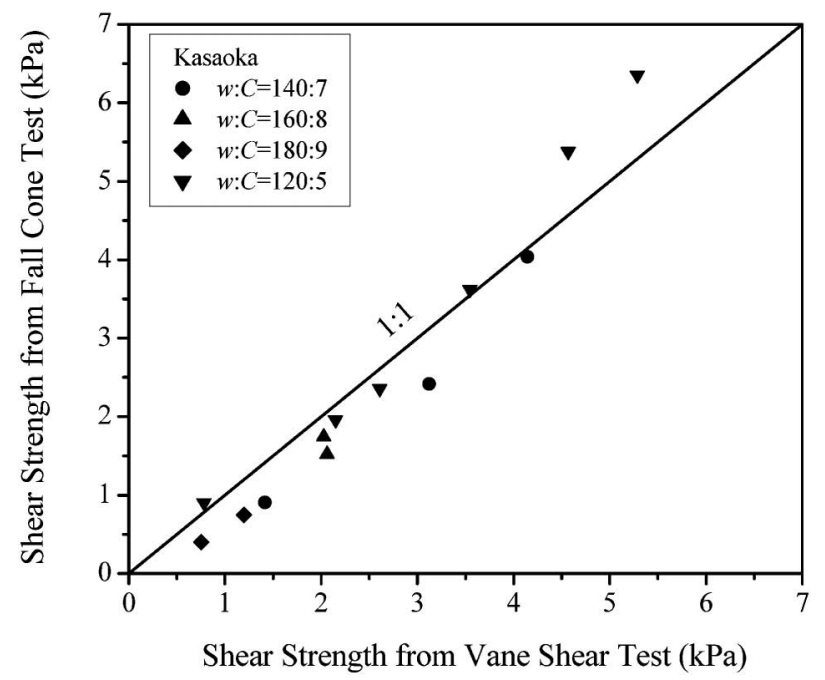

Fig. 10. Comparison of shear strength from fall cone and vane shear tests

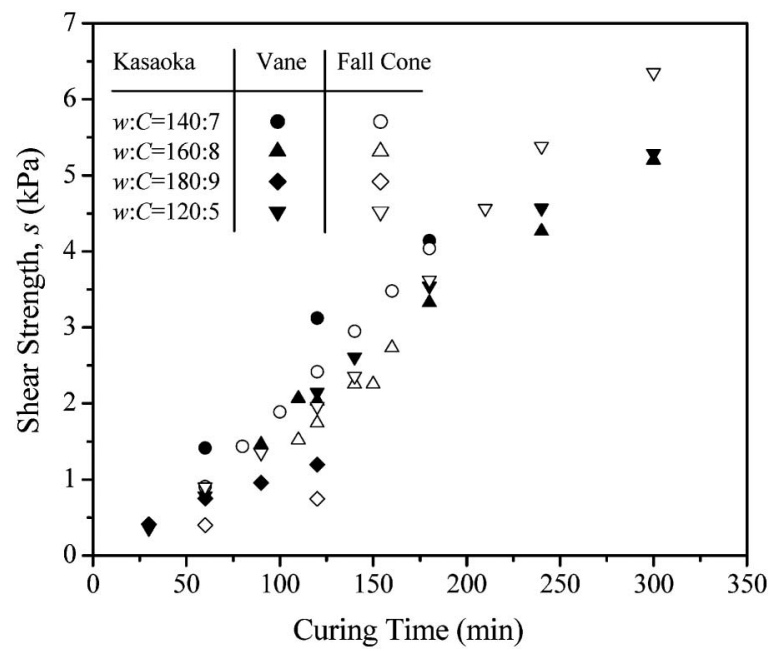

Fig. 11. Variation in shear strength from fall cone and vane shear tests with curing time

sites. However, in order to observe a wide range of strengths with certain accuracy, the weight of the cone should be changed according to the strength.

\section{STRENGTH AND STIFFNESS RELATIONSHIP}

The correlation between strength and stiffness for cement-mixed soil possessing relatively high levels of strength has already been studied by many researchers (Terashi et al., 1983; Lee et al., 2005; Flores et al., 2010). In this chapter, the authors will examine how to change the behavior of CTS according to different mixtures of water and cement contents and also soil properties, mainly focusing on strength and stiffness during the initial stages of curing or a lower strength range.

In addition to Fujinomori and Kasaoka clays, CTS samples have been prepared from Tokyo Bay clay at longer curing times to confirm the validity of the relation be- 


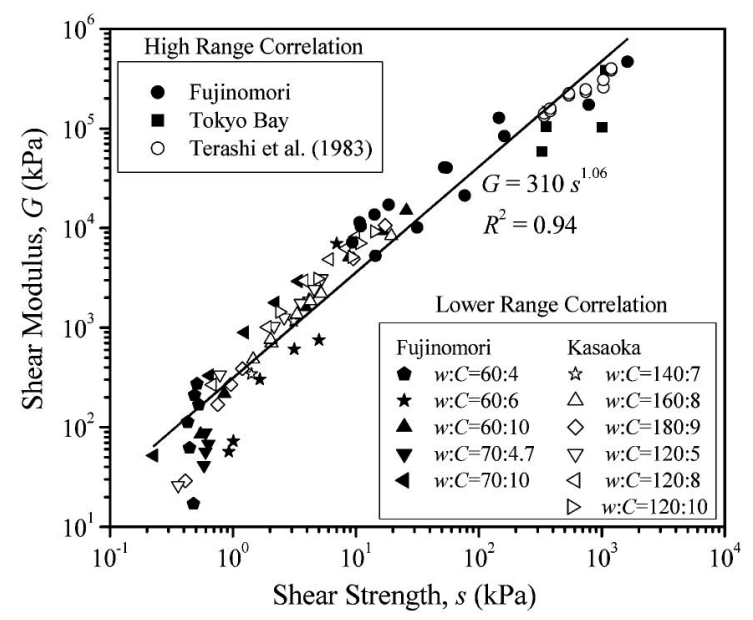

Fig. 12. Wide range correlation between $G$ and $s$

tween $G$ and the strength for high strength ranges. Figure 12 shows the correlation between $G$ and the shear strength derived from the present study, together with the results of tests conducted by Terashi et al. (1983). In the relation indicated by the "high range correlation", the strength, including that by Terashi et al. (1983), was measured by unconfined compression tests. Terashi et al. (1983) also carried out unconsolidated undrained (UU) triaxial tests on CTS samples under various levels of confining pressure and confirmed the validity of the shear strength as $s=q_{\mathrm{u}} / 2$. This has also been proposed by Tsuchida and Egashira (2004) for the design of CTS materials. As has already been mentioned, the $G$ value in this study was obtained by bender element testing, while Terashi et al. measured $G$ by resonant column testing. It should be noted that since unconfined compression tests require a certain level of strength, so that the sample will be strong enough to stand on its own, the lowest $s$ value obtained from these tests was about $10 \mathrm{kPa}$.

It is of interest that a linear relation between $G$ and $s$ also exists over 4 orders of magnitude for $G$ and $s$, i.e., $s$ ranges between $0.2 \mathrm{kPa}$ and $2000 \mathrm{kPa}$. It is found that the relation can be fitted quite well by a power function with a regression coefficient of about $94 \%$, as expressed in Eq. (5), namely,

$$
G=310 s^{1.06}
$$

It should be noted that the power of $s$ is very close to 1.0 , indicating that $G$ is about 300 times greater than $s$, regardless of the strength magnitude or $G$. It is well known that employing seismic waves, such as in a surface wave exploration, can be a very effective way of confirming the quality after the filling of the CTS. Using the above relation, the strength can easily be estimated from a seismic survey.

However, an outlying point in Fig. 12 indicates that at low strength, $G$ is relatively smaller than that expected based on Eq. (5). This may be due to some errors in testing or may indicate the true behavior. The point may in part be explained by the difference in accuracy between the bender element tests and the vane tests, as previously

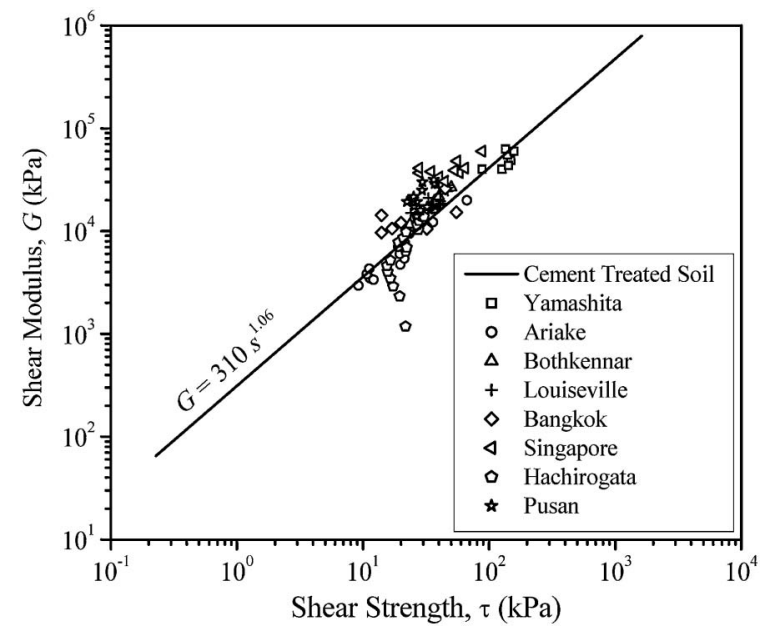

Fig. 13. Correlation between $G$ and $s$ of cement-treated soil and natural clays

noted. In addition, one should recall that inconsistency exists in the relationships shown in Figs. 4(b) and 7(b), where the normalized strength does not always increase with curing time, although there is a clear relation between normalized $G$ and the curing time. It is inferred that when CTS is in a liquid state, the effect of viscosity, or the rate effect, becomes so significant that the relation between $G$ and $s$ established for relatively high levels of strength may not exist. To confirm this inference, further research is required from the viewpoint of viscosity.

Furthermore, to check the applicability of Eq. (5) with other materials, the relation between $G$ and $s$ was plotted with correlations of natural clays investigated by in situ testing from various parts of the world, as shown in Fig. 13. The $G$ values for all the natural clays were determined using Seismic Cone Penetration Tests (SCPT). The strength was mostly obtained using Field Vane Tests, except for those of Yamashita and Bangkok clays, which were measured by Unconsolidated Undrained and Unconfined Compression tests, respectively. Tests were carried out by the authors' geotechnical group, except for those performed by Bothkennar and Louiseville, whose data are referenced in Hamouche et al. (1995) for Louiseville and Nash et al. (1992) for Bothkennar. Details on the properties of other natural clays may be found in Tanaka et al. (2001a, b). As can be seen from the figures, it is interesting to note that the strength and stiffness correlation of natural clays is concentrated around the relationship based on Eq. (5). It is implied that the mechanism of the CTS behavior is remarkably similar to that of natural clays.

\section{CONCLUSIONS}

The hardening process of CTS during the initial stages of curing has been studied by means of various laboratory testing methods, namely, bender element, vane shear, fall cone and unconfined compression tests. Based on the experimental results presented in this paper, the main 
conclusions are as follows:

1) Changes in CTS stiffness at any phase are easily observed using bender element tests. The minimum shear wave velocity detectable from this study is about 2.8 $\mathrm{m} / \mathrm{s}$, corresponding to a shear modulus of about 12 $\mathrm{kPa}$.

2) It was found that the shear strength measured by the vane and the fall cone tests is similar. It is useful to determine the shear strength of cement-mixed soil at the early stages of curing by fall cone tests, because the times required to follow the procedure and to complete the fall cone tests are considerably shorter than those of the vane tests.

3) The "setting time", prevalent in concrete, also exists in CTS.

4) It is not recommended to use the $W / C$ ratio to determine the quantity of cement with a wide range of water contents and different soils. The concept of applying the $W / C$ ratio should only be considered in limited cases.

5) A relationship between the shear modulus and the shear strength for a wide range of values is proposed as approximately $G=300 \mathrm{~s}$, where $S$ is the shear strength. This relation serves as a useful tool for monitoring the quality of materials in practice, since the shear wave velocity can easily be investigated in the field.

6) The above correlation is found to be almost the same as that for natural clays.

\section{ACKNOWLEDGEMENTS}

This research was partially supported by the Program for Promoting Fundamental Transport Technology Research from the Japan Railway Construction, Transport and Technology Agency (JRTT). The authors gratefully acknowledge the funding.

\section{REFERENCES}

1) Flores, R. D. V., Emidio, G. D. and Impe, W. F. V. (2010): Smallstrain shear modulus and strength increase of cement-treated clay, Geotechnical Testing Journal, 33(1), 62-71.

2) Hamouche, K. K., Leroueil, S., Roy, M. and Lutenegger, A. J. (1995): In situ evaluation of $K_{0}$ in eastern Canada clays, Can. Geotech. J., 32, 677-688.

3) Hansbo, S. (1957): A new approach to the determination of the shear strength of clay by the fall-cone test, Proc. R. Swed. Geotech. Inst. , No. 14.

4) Horng, V., Tanaka, H. and Obara, T. (2010): Effects of sampling tube geometry on soft clayey sample quality evaluated by nondestructive methods, Soils and Foundations, 50(1), 93-107.

5) Jeong, S. W., Locat, J., Leroueil, S. and Malet, J. P. (2010): Rheological properties of fine-grained sediment: the roles of texture and mineralogy, Can. Geotech. J., 47, 1085-1100.

6) Kawaguchi, T., Mitachi, T. and Shibuya, S. (2001): Evaluation of shear wave travel time in laboratory bender element test, Proc. 15th ICSMGE, 1, 155-158.

7) Lee, F. H., Lee, Y., Chew, S. H. and Yong, K. Y. (2005): Strength and modulus of marine clay-cement mixes, Journal of Geotechnical and Geoenvironmental Engineering, 131(2), 178-186.

8) Miura, N., Horpibulsuk, S. and Nagaraj, T. S. (2001): Engineering behavior of cement stabilized clay at high water content, Soils and Foundations, 41(5), 33-45.

9) Nash, D. F. T., Powell, J. J. M. and Lloyd, I. M. (1992): Initial investigations of the soft clay test site at Bothkennar, Géotechnique, 42(2), 163-181.

10) Otani, J., Mukunoki, T. and Kikuchi, Y. (2002): Visualization for engineering property of in-situ light weight soils with air foams, Soils and Foundations, 42(3), 93-105.

11) Satoh, T., Tsuchida, T., Mitsukuri, K. and Hong, Z. (2001): Field placing test of lightweight treated soil under seawater in Kumamoto port, Soils and Foundations, 41(5), 145-154.

12) Shibuya, S., Hwang, S. C. and Mitachi, T. (1997): Elastic shear modulus of soft clays from shear wave velocity measurement, Géotechnique, 47(3), 593-601.

13) Tanaka, H., Locat, J., Shibuya, S., Tan, T. S. and Shiwakoti, D. R. (2001a): Characterization of Singapore, Bangkok and Ariake clays, Can. Geotech. J., 38, 378-400.

14) Tanaka, H., Shiwakoti, D. R., Mishima, O., Watabe, Y. and Tanaka, M. (2001b): Comparison of mechanical behavior of two overconsolidated clays: Yamashita and Louiseville clays, Soils and Foundations, 41(4), 73-87.

15) Terashi, M. and Tanaka, H. (1981): Ground improved by deep mixing method, Proc. 10th Int. Conf. on Soil Mech. \& Found. Eng., Stockholm, 3, 777-780.

16) Terashi, M., Tanaka, H., Mitsumoto, T., Homma, S. and Ohashi, T. (1983): Fundamental properties of lime and cement treated soils (3rd report), Report of the Port and Harbor Research Institute, 22(1), 69-96, in Japanese.

17) Tsuchida, T. (1995): Super geo-material project in coastal zone, Proc. Int. Symp. on Coastal Ocean Space Utilization COSU'95, Yokohama, 22-31.

18) Tsuchida, T., Takeuchi, D., Okumura, T. and Kishida, T. (1996): Development of light-weight fill from dredgings, Proc. Environmental Geotechnics, Balkema, 415-420.

19) Tsuchida, T. and Egashira, K. (2004): The Lightweight Treated Soil Method: New Geomaterials for Soft Ground Engineering in Coastal Areas, A.A. Balkema Publisher, London.

20) Viggiani, G. and Atkinson, J. H. (1995): Interpretation of bender element tests, Géotechnique, 45(1), 149-154.

21) Wood, D.M. (1985): Some fall-cone tests, Géotechnique, 35(1), 64-68.

22) Yamashita, S., Kawaguchi, T. Nakata, Y., Mikami, T., Fujiwara, T. and Shibuya, S. (2009): Interpretation of international parallel test on the measurement of $G_{\max }$ using bender element, Soils and Foundations, 49(4), 631-650. 